\title{
Primary motivations of tourists visiting Galápagos: do tourists visit the archipelago to learn about evolution?
}

\author{
Clayton Mazur, Tiffany Galush, Randy Moore and Sehoya Cotner *i)
}

\begin{abstract}
Background: The Galápagos archipelago is known worldwide for its contributions to Charles Darwin's theory of evoIution by natural selection, and the islands continue to support studies in evolutionary biology. Yet despite the strong association of Galápagos with evolutionary biology, it is unknown if tourists—approaching 200,000 individuals annually_come to Galápagos with a specific interest in learning about evolution. Prior work has established that Galápagos National Park guides are proud of the association between the islands and evolution, yet on average do not do well on a test of basic evolutionary concepts. The work described herein is an attempt to clarify, via in-person surveys on tourists during the summer of 2016, whether tourists are motivated to visit Galápagos by an interest in evolution.

Results: Of the 109 tourists who answered the question "How interested were you in this trip to Galápagos?" all but one indicated that they were interested or extremely interested in their trip. Only two mentioned a specific interest in learning about evolution or the relationship between the islands and the history of evolutionary thought. For most people, seeing animals - in general or specifically identified animals such as the giant tortoises—was the primary motivation for coming to Galápagos. Unusual animals, snorkeling, and visiting a remote location all averaged above 4.0 on a 5.0-point scale, indicating that these aspects of the archipelago are very-to-extremely appealing to tourists. When average responses for 22 items were ranked from most to least appealing, evolution-related items came in 14th, 17th, 18th, and 20th. However, consequences of evolutionary processes, such as unusual animals and biodiversity, rank higher than either of the four evolution-specific items.

Conclusions: Given tourists' primary interest in the islands' endemic wildlife, we find little reason for concern over the guides' lack of specific evolution-related content knowledge. More critical to both guides and tourists are the impacts of population growth and increased tourism to the islands. Stakeholders can best serve the interests of the growing tourist population and the vigor of the Galápagos economy via conservation efforts-by developing and supporting programs that mediate the concerns raised by ecologists, protecting the islands'fragile habitat, and regulating commercial land use. In addition, a better understanding of tourists' motivations may provide opportunities to explore connecting evolutionary concepts to visitor interests.
\end{abstract}

Keywords: Galápagos islands, Charles Darwin, Evolution, Biodiversity, Tourism, Ecuador

*Correspondence: sehoya@umn.edu

Department of Biology Teaching and Learning, University of Minnesota,

420 Washington Avenue SE, Minneapolis, MN 5545, USA 


\section{Introduction}

In 1835, HMS Beagle visited the Galápagos Islands, ferrying its unofficial naturalist, Charles Darwin. Darwin (1809-1882) spent 3 weeks exploring four islands in the archipelago, making observations and collections, and taking notes. Many of the specimens he collected, along with the notes he took, formed the basis for his emerging thoughts on the origin of variation, and are cited accordingly in his famous book, The Origin of Species. Since that visit, Galápagos has been a place of interest for whalers, fishermen, convicts, and countless subsequent naturalists and scientists (Moore and Cotner 2013). Galápagos, known worldwide as the cradle of thought for Charles Darwin's theory of evolution by natural selection, continues to serve as a locus for studies in evolutionary biology.

The islands' historic-and continued-association with evolution is advanced throughout the archipelago.
From the moment tourists disembark on the island of San Cristóbal or Baltra, they are confronted with Darwin and the history of evolutionary thought. Darwin is commemorated in street names, bronze busts, local parks, and landmarks in nearly every town on inhabited islands. Evolution adorns souvenirs, t-shirts, the names of businesses and boats, and is the basis of performances presented by local school children (Fig. 1). The idea of evolution is everywhere in Galápagos; it is difficult for even the most uninterested of visitors to ignore evolution here.

The notoriety of Galápagos as the epicenter of evolutionary thought has stimulated a tourist-based economy. The islands host over 180,000 tourists annually, nearly 6 times the permanent population of the islands. Tourism benefits the Galápagos economy both directly (e.g., generates revenue streams) and indirectly (e.g., decreased
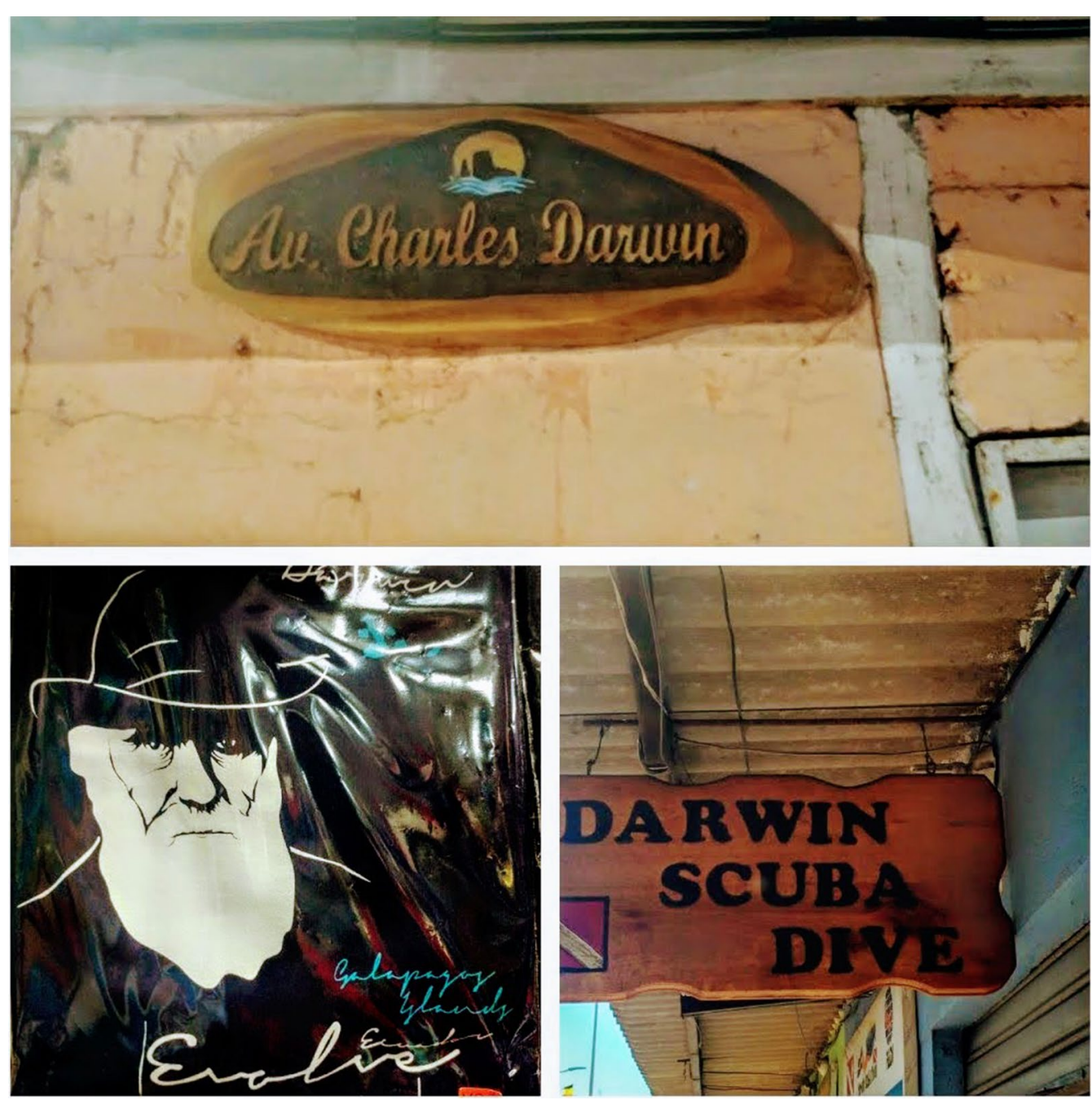

Fig. 1 Images from Galápagos. References to Charles Darwin are everywhere in Galápagos 
unemployment rate). Currently, tourism constitutes 51\% of the islands' economy (Eplera et al. 2006; Galapagos Conservancy 2017). Tourists come from all over the globe to pursue a variety of interests including seeing unusual animals, photography, snorkeling, and hiking. Tourists are typically accompanied by Galápagos National Park (GNP) guides who, among other topics, highlight the role of Galápagos in the history of evolutionary thought. Despite the strong association of Galápagos with evolutionary biology, it is unknown if tourists come to Galápagos with a specific interest in learning about evolution.

A previous study assessed the acceptance and knowledge of the theory of evolution among GNP guides (Cotner et al. 2017). Eighty-nine percent of GNP guides are proud of the connections between Galápagos and evolution, $83 \%$ enjoy discussing evolution, and $97 \%$ are confident in their knowledge of evolution. Although GNP guides have high acceptance of evolution, they know little about the principle tenets of evolutionary theory (i.e., only $23.4 \%$ can identify the definition of evolution by natural selection; Cotner et al. 2017).

GNP guides are conduits of information linking tourists to evolution, a key part of the culture and history of the Galápagos. Therefore, the disconnect between guides' confidence and knowledge of evolution may have implications for how evolution is perceived by interested tourists. If these tourists visit Galápagos to learn about evolution-whether the history of evolutionary thought or the actual science of evolution-then they may get only part of the story. That is, they may learn about Darwin's visit and the islands' role in this aspect of the history of science, but they may not learn much about what evolution is and is not. Given that many tourists originate from countries in which evolution education may be compromised (e.g. by politics or religion), a visit to Galápagos could be an important opportunity for informal science education in this topic. However, if tourists are not visiting the islands with the goal of learning about evolution, the guides' weak grasp of the science may be irrelevant. To determine the significance of previous work in this subject, our study seeks to identify the primary motivations driving tourists to visit Galápagos.

\section{Methods}

To determine tourists' motivations for visiting Galápagos, we surveyed 111 self-identified tourists on the islands of Santa Cruz $(n=26)$, Isabela $(n=26)$, and San Cristóbal $(\mathrm{n}=58)$ from 21 August through 28 August 2016. The survey consisted of 33 total items. The first few survey items were demographic (i.e., age, gender, country of origin, level of education); the first two (non-demographic) survey items defined the primary motivation for a visit to the islands and interest in that current visit. These items were followed by 26 Likertscale items aimed at ranking potential motivations for visiting the islands (e.g., "Snorkeling"; "Ecotourism"; "Hiking Volcanoes"). These items were generated through a series of informal conversations with GNP guides and US-based colleagues (scientists and educators) responding to our specific question, "Why do you think people go to Galápagos?" From these responses, we generated a list of 26 items we considered potential motivations for visiting the islands. Because we were unable to pilot the survey, we included an "other" option for open responses. Four response items specifically addressed evolution: "Learning about Evolution," "Learning about the History of Evolutionary Thought," "Learning about Charles Darwin," and "Visiting the Charles Darwin Research Station." Tourists were asked to rank their interest in each of these 26 items (specifically as a reason for visiting Galápagos) on a scale of "Not Appealing" to "Extremely Appealing." Due to the high number of Ecuadorian and other Latin-American citizens visiting Galápagos (Proaño and Epler 2006), the survey was created in both English and Spanish. Two native Latin-American Spanish-speakers, including one professional translator, checked the survey for readability and accuracy. The full survey is available as Additional file 1.

Tourists were approached in public spaces in three towns: Puerto Ayora on Isla Santa Cruz; Puerto Villamil on Isabela, and Puerto Baquerizo Moreno on San Cristóbal. All tourists were approached and identified as adult (i.e., > 18 years old) by two people-one fluent in Spanish and one fluent in English. All individuals were surveyed outside of GNP. To minimize bias due to the selection of items listed on subsequent survey questions, the first two questions addressing an individual's primary motivation for visiting Galápagos and their overall interest in their trip were asked orally, and recorded by an investigator (CM, SC, or TG). Respondents were then free to fill out the remaining items at their leisure. At least one investigator stayed with each tourist until he or she completed the survey and answered questions about research aims or clarified survey items. Each tourist who completed the survey was given a pair of "Galápagos 2016" sunglasses, valued at $\sim \$ 2$ USD.

Tourists were notified orally and in writing that they could omit any survey item. All individuals completed the survey within $15 \mathrm{~min}$ and independently of other respondents. The survey, consent statement, and procedures were exempt from full review by the University of Minnesota's Institutional Review Board (IRB). However, each respondent was offered a business card bearing contact information for the primary investigator (SC) and the University of Minnesota IRB office so that they could 
subsequently ask questions about the survey, request that their response be withdrawn, or comment about the work.

Surveys were completed on paper. Likert-scale responses were converted to numerical responses for statistical analysis, with "Extremely Appealing" receiving a 5 and "Not at All Appealing" a 1. Numerical responses were categorized into "disinterested" (1-2), "neutral" (3), and "interested" (4-5) to compare broadly across items. Likert-scale responses were evaluated via Wilcoxon tests to compare means, and, with multiple categories, oneway ANOVAs. Respondents who did not complete a Likert-scale item, or who indicated two responses to an item, were excluded from analysis to remain consistent across all 26 items.

\section{Results}

\section{Who goes to Galápagos?}

Of the 111 tourists who completed the survey, $23.4 \%$ were located on Santa Cruz, $23.4 \%$ on Isabela, and $52.3 \%$ were on San Cristóbal. Just over half of the tourists surveyed (53.0\%) were female. Most tourists were visiting from mainland Ecuador (23.0\%), the United States (14.0\%) or the United Kingdom (14.0\%), with other countries (e.g., Colombia, Bulgaria, Spain, France, Germany, Argentina, Australia) represented in smaller proportions. Most of the respondents were between 26 and 44 years old; however, four respondents were 65 years of age or older.

Thirty-six distinct occupations were represented among the tourists. Of the 91 tourists who indicated an occupation and were not retired, $28.6 \%$ were students, followed by health care professionals $(17.6 \%)$, scientists and engineers (14.2\% combined), managers $(8.8 \%)$, communicators (e.g., "writer," "journalist"), information technologists ( $4.4 \%$ each), financiers, teachers, and merchants (3.3\% each), volunteers $(2.2 \%)$, and other miscellaneous occupations totaling $9.9 \%$.

Of the 92 tourists for whom we had interpretable answers for the "highest education level" item, 1.1\% had only attended grade school, $5.4 \%$ were high school graduates, $48.9 \%$ were undergraduates attending university, $16.3 \%$ had a bachelor's degree, $15.2 \%$ had a master's degree, and $6.5 \%$ had a doctorate degree. A specific degree (either master's or doctorate) could not be determined for an additional $6.6 \%$ of respondents with "graduate degree[s]." These categories were binned into "no college," "college," and "post-graduate" fields for further analysis (see below).

\section{Why do tourists visit Galápagos?}

All 111 tourists answered the question "Thinking back to your pre-trip planning, what was your primary motivation for visiting Galápagos?" We categorized responses that were given by more than one tourist (Table 1). Many tourists indicated that seeing animals (e.g., "iguanas," "[to see] the Galápagos Tortoise") was their primary motivation for being in Galápagos, while other responses ranged from "[o]ffered on the internet for a decent price" and " $[\mathrm{s}]$ he wanted to go," to "[because it is] a vacation that is different than anything else." Only two of these open-ended

Table 1 Categorization of tourists' primary motivations for visiting Galápagos by general topic

\begin{tabular}{|c|c|c|}
\hline Topic & Number of respondents & Example responses \\
\hline \multicolumn{3}{|c|}{ Characterization of tourists' primary motivations } \\
\hline Animals/nature & 62 & "See the Galapagos Tortoise;" "To see nature that is about to go extinct" \\
\hline Unique location & 17 & "A vacation that is different than everything else" \\
\hline Part of South America tour & 9 & "Part of a bigger South America trip;;" 28-day excursion" \\
\hline Bucket list item & 10 & "Bucket list item;" "Always wanted to come to Galapagos" \\
\hline Landscape & 7 & "The landscape, animals, and history" \\
\hline Beaches & 6 & "White beaches" \\
\hline Ecotourism & 5 & "Ecotourism haven;" [A] place that's cared for regulation about wildlife in place" \\
\hline Family & 4 & "Family and tourism" \\
\hline Diving & 4 & "Exploring biodiversity underwater" \\
\hline Honeymoon & 4 & "Honeymoon; bucket list vacation" \\
\hline Schedule flexibility & 3 & "Always wanted to come to Galapagos; had some time" \\
\hline Ecuadorian nationalism & 3 & "To get to know something important to the country" \\
\hline Other & 3 & "Offered on the internet at a good price;" "She wanted to go" \\
\hline Island history & 2 & "[H]istory associated with animals" \\
\hline Darwin and evolution & 2 & "Nature and environment; Darwin" \\
\hline Tourism & 2 & "Family and tourism" \\
\hline
\end{tabular}


responses identified evolution or evolutionary thought as a primary motivation to visit Galápagos (e.g., "Darwin and [the] history associated with [the] animals" and "Darwin's journey and evolution"). Of 109 tourists who answered the question "How interested were you in this trip to Galápagos?" 99.1\% indicated that they were interested or extremely interested in their trip, while a single respondent indicated a disinterest in the trip.

Between 103 and 109 tourists responded to the Likertscale survey items. Variation in responses between tourists who were disinterested and interested was present for all items (Fig. 2); however, average appeal for all items was $>3.0$ (Table 2), suggesting that tourists were generally interested in all the potential motivations listed in the survey.

"SCUBA diving," "Speaking Spanish," "Crossing the Equator" and "Living on a Boat" were excluded from this analysis, as they did not pertain to all tourists we encountered. Many visitors do not have the opportunity to go diving, cross the equator, or live on a boat. Also, the ability to speak Spanish is unlikely to be appealing to native Spanish speakers, of which there were many.

Unusual animals, snorkeling, and visiting a remote location all averaged $>4.0$ on a 5.0-point scale, indicating that these aspects of the archipelago are very-toextremely appealing to tourists. In a comparison of mean responses (using a 1-sample Wilcoxon test), unusual animals were significantly more appealing than the second choice, snorkeling ( $\mathrm{W}=7642, \mathrm{p}<0.05)$. No other gap in the average appeal of two items exceeded the 0.55 gap between unusual animals and snorkeling or was statistically significant. In contrast to those items with high appeal, geology (3.04) and unusual plants (3.23) appealed least to tourists. When average responses for the 22 items were ranked from most to least appealing (Table 2), interest in learning about evolution ranked 14th, interest in

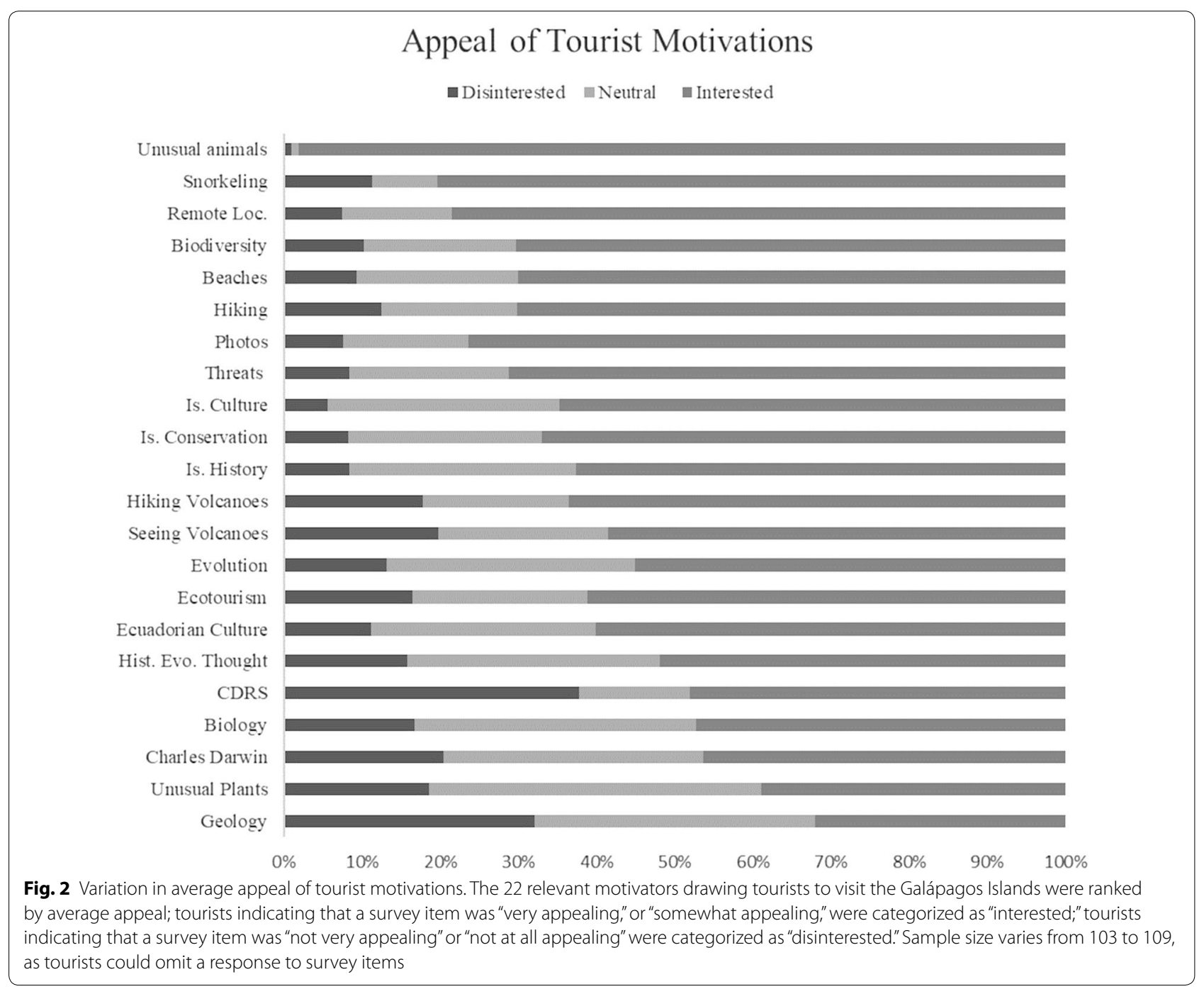


Table 2 Ranked appeal of tourist motivations for visiting Galápagos

\begin{tabular}{lcl}
\hline Motivation & Rank & $\begin{array}{l}\text { Average (on } \\
\mathbf{1 - 5} \text { scale) }\end{array}$ \\
\hline Ranked appeal of 22 Likert-scale items & & \\
Unusual animals & 1 & 4.73 \\
Snorkeling & 2 & 4.18 \\
Remote location & 3 & 4.07 \\
Biodiversity & 4 & 3.91 \\
Beaches & 5 & 3.91 \\
Hiking & 6 & 3.87 \\
Photos & 7 & 3.84 \\
Threats to biodiversity & 8 & 3.83 \\
Island culture & 9 & 3.82 \\
Island conservation & 10 & 3.79 \\
History of the islands & 11 & 3.75 \\
Hiking volcanoes & 12 & 3.72 \\
Seeing volcanoes & 13 & 3.61 \\
Evolution & 14 & 3.61 \\
Ecotourism & 15 & 3.60 \\
Ecuadorian culture & 16 & 3.60 \\
History of evolutionary thought & 17 & 3.46 \\
Visiting the CDRS & 18 & 3.43 \\
Biology & 19 & 3.43 \\
Charles Darwin & 20 & 3.36 \\
Unusual plants & 21 & 3.23 \\
Geology & 22 & 3.04 \\
\hline
\end{tabular}

Twenty-two Likert-scale items were ranked by average appeal on a scale of $1-5$, with 5 being "extremely appealing." Sample size varies from 103 to 109, as tourists could omit a response to survey items

the history of evolutionary thought ranked 17th, visiting the Charles Darwin Research Station ranked 18th, and learning about Charles Darwin ranked 20th. Notably, consequences of evolutionary processes, including biodiversity $(3.91$; 4th), rank higher than either of our four evolution-specific items.

\section{Who visits Galápagos for evolution?}

Of the nine respondents that indicated that "Learning about Evolution" was "Extremely Appealing," 60\% were female; respondents ranged from 18 to 74 years of age, and all but one was college educated. Countries of origin in this sample were not disproportionately represented relative to other tourists (i.e., tourists visiting from one country did not have an increased interest in evolution compared to tourists visiting from other countries).

Of the 16 respondents that indicated that "Learning about the History of Evolutionary Thought" was "Extremely Appealing," 50\% were female; respondents ranged from 18 to 84 years of age, and all who indicated their level of education $(n=14)$ were college educated, with three having a Doctorate degree and one having a Master's degree. Tourists originating from Australia, Ecuador, the UK, and Chile were overrepresented relative to tourists not expressing interest in learning about evolutionary thought, while tourists from the USA were underrepresented.

Only level of education and gender predicted one's interest in evolution. Specifically, individuals without a college or post-graduate degree were significantly less likely than their college-educated counterparts to rank any of the following motivations highly: learning about evolution (F-ratio $=3.155 ; \mathrm{p}<0.05)$, learning about the history of evolutionary thought $($ F-ratio $=4.2155 ; \mathrm{p}<0.05)$, learning about Charles Darwin (F-ratio $=3.1396 ; \mathrm{p}<0.05)$, and visiting the Charles Darwin Research Station (F-ratio $=8.0468 ; \mathrm{p}<0.001$ ).

Females, who averaged 3.52 (between "somewhat appealing" and "very appealing") on the eleventh survey item were significantly more likely than men, who averaged 3.17, to indicate "learning about Charles Darwin" as a motivation for visiting the islands $(\mathrm{p}<0.05)$. Females (average of 3.62 on the 22nd survey item) also claimed more interest in visiting the Charles Darwin Research Station than did men (average 3.25; $\mathrm{p}<0.05$ ). For no other items did the sexes differ significantly.

Age was not a predictor of differences in evolutionrelated preferences. The ages differed significantly on only two of the 26 categories: younger tourists were most likely to express a desire to practice their Spanish $(p<0.05)$, and older adults were most interested in crossing the equator $(\mathrm{p}<0.05)$.

\section{Discussion}

There are notable limitations to our study. First, we surveyed a non-random group of tourists, as tourists were sampled opportunistically as they were encountered. Second, due to tourists traveling in pairs or in small groups, conditions in which all tourists were surveyed, responses were non-independent. Third, as is the case with all survey data, we must make assumptions about the participants' understanding of topics such as biodiversity, distinctions between biology and biodiversity and their connections to evolutionary concepts, and the extent to which broad topics such as "history of the islands" included, in the tourists' minds, specific events such as the HMS Beagle narrative and Darwin's work in the islands. Finally, we acknowledge possible ambiguity in how some of the terms were understood by the respondents; for example, we did not specifically define "biodiversity" or other potentially novel terms. However, despite these limitations, the current study is the first, to our knowledge, to address if an interest in evolution is a 
primary motivation for visiting Galápagos. Here we discuss our results considering previous work elucidating the acceptance and knowledge of evolution by another important population in Galápagos: GNP guides.

Previous work by Cotner et al. (2017) aimed to determine the attitudes towards, and knowledge of, evolution by GNP guides living and working on Santa Cruz, Isabela, and San Cristóbal. GNP guides have high acceptance of the theory of evolution, as measured by the MATE [higher than Galápagos teachers; Bell and Sahgal (2014); Cotner et al. (2016)], yet performed poorly on the KEE (Cotner et al. 2017). When asked, on an open-ended survey item, what they like discussing most with tourists, $32.0 \%$ of the 56 guides who responded indicated that geology was their favorite topic of discussion. Island culture (26.0\%) and specific organisms (e.g., sea lions; $26.0 \%)$ ranked above evolution (17\%) as favorite topics of discussion. Interestingly, geology is the least interesting topic to the tourists in our sample, suggesting an unfortunate misalignment of preferences between guides and tourists.

GNP guides serve and inform over 180,000 tourists annually (Honey 2008), as tourists must be accompanied by a guide when visiting nearly every part of GNP. Most members of the general public have visited museums featuring evolution; therefore, tourists likely have prior knowledge of Galápagos' connection to evolution before embarking on their trip (Diamond et al. 2007; National Science Board 2006). Tourists are further inundated with the idea of evolution subsequent to their arrival in Galápagos. Alongside these tourists' daily exposure to Darwin and evolutionary history via busts, museums, and historical landmarks, GNP guides have the potential to directly inform tourists about both Darwin's journey (i.e., the narrative of evolutionary history) and the science of evolution. The uncoupling of a guide's perception of evolution and his or her knowledge of evolutionary concepts (e.g., natural selection; evolutionary fitness) may have implications for how effectively these topics are communicated to interested tourists.

We question which is more important to convey to visitors to the islands-positive perceptions of evolution, or accurate explanations of evolutionary processes? In the US, many sampled populations [e.g., in Minnesota (Moore and Cotner 2009a, b, c) and Iowa (Rice et al. 2011)] perform better on tests about evolution than do guides in Galápagos, yet these same populations tend to score much worse on the MATE (Moore and Cotner 2009a, b, c). In these examples, perceptions and knowledge of evolution have been decoupled in a manner that is opposite that of the guides, who love evolution but perform worse on the KEE. Furthermore, there is evidence that simply teaching the facts of evolution is insufficient for increasing acceptance, especially in a population whose group identity may include rejecting evolution (e.g., conservative Christians; Walker et al. 2017). Thus, for individuals who subconsciously reject evolution to protect their group identity (à la Identity Protective Cognition; Kahan et al. 2007), exposure to guides that express positive perceptions of evolution may be more effective than a biology lecture.

There is a fundamental disconnect between GNP guides' preferred topic of discussion (geology) and the tourists' primary motivation (animals) for visiting Galápagos. Yet, this disconnect does not concern an interest in evolution. Our results suggest that the appeal of seeing Galápagos' unusual and endemic animals (e.g., Galápagos tortoises, Galápagos penguins, and marine iguanas) is overwhelmingly the primary motivator bringing tourists to the islands. GNP guides enjoy discussing geology most, but geology ranks last in appeal among tourists. This disconnect in the guide-tourist relationship is partially mediated by the $38.9 \%$ of GNP guides who favored discussing specific organisms, animal behavior, or endemic or unique fauna (Cotner et al. 2017). General discussion of evolution was favored by only $17 \%$ of GNP guides, and learning about evolution was the primary motivator for only two tourists. However, even these two individuals indicated higher interest in unusual animals than they did in learning about evolution.

Level of education was a strong predictor of an interest in evolution; all but one of the respondents who indicated evolution or the history of evolutionary thought as "highly appealing" were college educated. The positive correlation between interest in evolution and education level is consistent with studies involving student populations (Paz-y-Miño and Espinosa 2009; Rissler et al. 2014). Respondents from the United States were underrepresented in their propensity to find evolution and the history of evolutionary thought "highly appealing" relative to respondents from other countries. A small sample size of nine and sixteen, respectively, may explain this bias. Yet, the US is unique, as one-third of the population believes in some form of creationism and rejects core tenets of evolution (PEW Research Center 2013). The influence of young-Earth creationism (YEC) and YEC organizations (e.g., Institute for Creation Research; Answers in Genesis) on the public opinion of evolution cannot be ignored and YEC beliefs have influenced the perception of evolution in education and US law (Lewin 1987; Moore and Cotner 2009a, b, c; Moore and Kraemer 2005).

Any concerns regarding the inaccurate education of tourists in evolution due to low KEE scores among GNP guides may be unfounded given tourists' relative disinterest in evolution and the history of evolutionary thought. Despite these concerns, GNP guides have demonstrated 
knowledge in Galápagos' historical connection to evolution (i.e., 91.8\% can identify the reason for Darwin's visit; Cotner et al. 2017) and they are proud of the connection between the islands and evolution. Additionally, though evolution may not be the favorite subject of discussion for many GNP guides, evolution is frequently discussed conceptually in its relation to biodiversity, island history, and the evolution-creationism controversy (SC and RM, personal observations). With evolution ranking below biodiversity and island history, the extent to which GNP guides discuss Darwin's journey and the theory of evolution is likely sufficient to satiate the interests of most tourists. Tourists indicating the science of evolution as a primary motivation for visiting the islands may be misinformed by GNP guides, but may also supplement information received by GNP guides with accurate information available on landmarks and in the Charles Darwin Research Station. Furthermore, although we cannot demonstrate this suspicion with the present study, we suspect that those individuals most interested in learning about evolution already know quite a bit about the central tenets of evolutionary biology.

Since GNP guides have a high acceptance of the theory of evolution, and research has demonstrated that teaching the concepts of evolution is easier than accepting the theory (Alters et al. 2002; Nehm et al. 2009; Nehm and Schonfeld 2007), targeted programs could be initiated to increase GNP guide's scientific knowledge of evolutionary concepts. Alternatively, guides could be instructed to relate evolutionary mechanisms to consequences of evolution such as biodiversity, endemism and unusual wildlife, and conservation- all of which are ranked as more motivating than evolution by tourists in our sample. Such programs may increase GNP guides' KEE scores and appeal to tourist motivations, but given tourists' primary interest in endemic wildlife, low KEE scores do not threaten the potential impact of GNP guides as informal educators of evolution. A proximal threat to the livelihood of GNP guides is the anthropogenic impacts of population growth and increased tourism to the islands. Increased population growth led to UNESCO placing GNP on its List of World Heritage in Danger in 2007 (Epler 2007), and the negative ecological effects of population growth and tourism are well established (Burger and Gochfeld 1993; French et al. 2010; Kenchington 1989; Romero and Wikelski 2002; Sarti 2016; Wikelski et al. 2004). While it is beyond the scope of the current study, we note that GNP or other local organizations (CDRS; Galápagos Conservancy) can best serve the interests of the growing tourist population, and, by extension, the vigor of the Galápagos economy, by developing and supporting programs that mediate the concerns raised by ecologists, protect the islands' fragile habitat, and regulate commercial land use.
In this way, GNP guides and officials can best preserve the unusual and iconic animals that serve as the primary motivation for nearly 200,000 tourist visits each year.

\section{Additional file}

Additional file 1. The complete survey administered in Galápagos during this study.

\section{Abbreviations}

GNP: Galápagos National Park; KEE: knowledge of evolution exam; MATE: measure of the acceptance of the theory of evolution; YEC: young Earth creationism

\section{Authors' contributions}

All authors contributed to the experimental design, survey administration, and/or drafting of the manuscript. All authors read and approved the final manuscript.

\section{Acknowledgements}

The authors gratefully acknowledge the Spanish-language consultation of Darío Castro and José Julián Moreno. Flannery Cotner provided valuable Spanish-language assistance during survey collection in Galápagos. We thank the Rubio family (especially Cecilia, Rafael, and Rafaela) for logistical support on Santa Cruz, and Roselyn Cameron for pre-trip advice.

\section{Competing interests}

The authors declare that they have no competing interests.

\section{Availability of data}

We are happy to share our data in whatever form the editors prefer.

\section{Ethics approval and consent to participate}

The University of Minnesota IRB judged this work as exempt from full review. All guides signed consent forms prior to completing the survey.

Funding

Not applicable.

\section{Publisher's Note}

Springer Nature remains neutral with regard to jurisdictional claims in published maps and institutional affiliations.

Received: 25 February 2018 Accepted: 31 July 2018

Published online: 09 August 2018

\footnotetext{
References

Alters BJ, Nelson CE, Mitton J. Perspective: teaching evolution in higher education. Evolution. 2002;56(10):1891-901.

Bell J, Sahgal N. Religion in Latin America: widespread change in a historically Catholic region. Washington, D.C: Pew Research Center; 2014.

Burger J, Gochfeld M. Tourism and short-term behavioural responses of nesting masked, red-footed, and blue-footed, boobies in the Galápagos. Environ Conserv. 1993;20(3):255-9. https://doi.org/10.1017/S037689290 0023043.

Cotner S, Graczyk H, Rodríguez Garcia JL, Moore R. In Galápagos ... and uncomfortable with evolution. J Biol Educ. 2016;50(2):115-9. https://doi. org/10.1080/00219266.2016.1175758.

Cotner S, Mazur C, Galush T, Moore R. Teaching the tourists in Galápagos: what do Galápagos National Park guides know, think, and teach tourists about evolution? Evol Educ Outreach. 2017. https://doi.org/10.1186/s1205 2-017-0072-4.
} 
Diamond J, Evans EM, Meagher T. Museums teach evolution. Evolution. 2007;61(6):1500-6. https://doi.org/10.1111/j.1558-5646.2007.00121.x.

Epler B. Tourism, the economy, population growth, and conservation in Galapagos. Charles Darwin Foundation: Santa cruz; 2007.

Eplera B, Watkinsb G, Cárdenasb S. Tourism and the Galapagos economy; 2006. French SS, DeNardo DF, Greives TJ, Strand CR, Demas GE. Human disturbance alters endocrine and immune responses in the Galapagos marine iguana (Amblyrhynchus cristatus). Horm Behav. 2010;58(5):792-9. https://doi. org/10.1016/j.yhbeh.2010.08.001.

Galapagos Conservancy. Tourism and population growth. Galapagos Conservancy: Fairfax; 2017.

Honey M. Ecotourism and sustainable development: who owns paradise? Washington, D.C: Island Press; 2008.

Kahan DM, Braman D, Gastil J, Slovic P, Mertz CK. Culture and identity-protective cognition: explaining the white-male effect in risk perception. J Empir Legal Stud. 2007:4(3):465-505.

Kenchington RA. Tourism in the Galapagos Islands: the dilemma of conservation. Environ Conserv. 1989;16(3):227-32.

Lewin R. Creationism case argued before Supreme Court. Science. 1987:235:22-4.

Moore R, Cotner S. Educational malpractice: the impact of including creationism in high school biology courses. Evol Educ Outreach. 2009a;2(1):95100. https://doi.org/10.1007/s12052-008-0097-9.

Moore R, Cotner S. Rejecting Darwin: the occurrence \& impact of creationism in high school biology classrooms. Am Biol Teach. 2009b;71(2):e1-4. https ://doi.org/10.1662/005.071.0204.

Moore R, Cotner S. The creationist down the hall: does it matter when teachers teach creationism? Bioscience. 2009c;59(5):429-35.

Moore R, Cotner S. Understanding Galapagos. New York: McGraw-Hill; 2013.

Moore R, Kraemer K. The teaching of evolution \& creationism in Minnesota. Am Biol Teach. 2005;67(8):457-66.

National Science Board. Science and engineering indicators 2006. National Science Board: Arlington County; 2006.
Nehm RH, Schonfeld IS. Does increasing biology teacher knowledge of evolution and the nature of science lead to greater preference for the teaching of evolution in schools? J Sci Teach Educ. 2007;18(5):699-723.

Nehm RH, Kim SY, Sheppard K. Academic preparation in biology and advocacy for teaching evolution: biology versus non-biology teachers. Sci Educ. 2009;93(6):1122-46. https://doi.org/10.1002/sce.20340.

Paz-y-Miño CG, Espinosa A. Acceptance of evolution increases with student academic level: a comparison between a secular and a religious college. Evolution. 2009:2(4):655-75. https://doi.org/10.1007/s12052-009-0175-7.

PEW Research Center. Public's views on human evolution. Washington, D.C: PEW Research Center; 2013.

Proaño ME, Epler B. Tourism in Galapagos: a strong growth trend. Galapagos Rep. 2006;2007:31-5

Rice JW, Olson JK, Colbert JT. University evolution education: the effect of evolution instruction on biology majors' content knowledge, attitude toward evolution, and theistic position. Evol Educ Outreach. 2011;4(1):137-44. https://doi.org/10.1007/s12052-010-0289-y.

Rissler LJ, Duncan SI, Caruso NM. The relative importance of religion and education on university students' views of evolution in the Deep South and state science standards across the United States. Evol Educ Outreach. $2014 ; 7(1): 24$.

Romero LM, Wikelski M. Exposure to tourism reduces stress-induced corticosterone levels in Galapagos marine iguanas. Biol Conserv. 2002;108(3):371-4.

Sarti B. The viability of further growth: an integrated analysis of ecotourism in the Galapagos Islands. Social Impact Research Experience (SIRE). 46; 2016. http://repository.upenn.edu/sire/46.

Walker JD, Wassenberg D, Franta G, Cotner S. What determines student accept ance of politically controversial scientific conclusions? J Coll Sci Teach. 2017:47(2):46-56

Wikelski M, Foufopoulos J, Vargas H, Snell H. Galápagos birds and diseases: invasive pathogens as threats for island species. Ecol Soc. 2004. https:// doi.org/10.5751/ES-00605-090105.
Ready to submit your research? Choose BMC and benefit from:

- fast, convenient online submission

- thorough peer review by experienced researchers in your field

- rapid publication on acceptance

- support for research data, including large and complex data types

- gold Open Access which fosters wider collaboration and increased citations

- maximum visibility for your research: over $100 \mathrm{M}$ website views per year

At $\mathrm{BMC}$, research is always in progress.

Learn more biomedcentral.com/submissions 